\title{
Rehumanización ancestral nativo-mestiza: una tejedura convivencial multicultural post-conflicto para Colombia
}

\author{
José Uriel Leal Zabala \\ Universidad de Cundinamarca, Colombia. \\ uritolima@hotmail.com
}

El ser humano posee el poder y el talento de expresarse de las más diversas y complejas maneras en su acto comunicativo y, es en su oralituridad y sus expresiones cinésicas y proxémicas, donde encarna su personalidad individual y colectiva, temperamento y carácter, para disoñar y co-crear su cotidianidad. Como el lenguaje y la ciencia es abstracción y el arte de con-versar es un proceso biodinámico, sinuoso, aleatorio y continuo de nuestra condición de hablante-seres, se ha querido implementar esta facultad para ir facilitando los procesos convivenciales post-conflicto en el aquí y el ahora.

Este ensayo se plantea como una contribución a la construcción de paz en Colombia y debe ser tomado como un intento real y simbólico de volver a tejer co-creativamente la cultura occidental y la cultura ancestral precolombina que nos hace nativos mestizos y que, a la fecha, nos marca en dolorosa y desgastante convivencia individual y colectiva.

[Es preciso que el autor incluya algunos párrafos en donde justifique la importancia de la cultura ancestral precolombina como alternativa de solución a los problemas de comunicación occidentales y presente casos patentes en donde se han llevado a cabo este tipo de procesos. Se recomienda incluir las reflexiones de Fals Borda sobre los Sentipensantes, en especial retomar apartes citados en el libro Fals Borda, Orlando, 1925-2008. Una sociología sentipensante para América Latina. Víctor Manuel Moncayo Compilador. Bogotá: Siglo del Hombre Editores y CLACSO, 2009. 492 p.; $21 \mathrm{~cm}$. De igual forma, citar el caso de la comunidad Dogon en África; hay un libro interesante 'Etnología y Lenguaje. La palabra en los Dogón' de Geneviève CalameGriaule]
[¿De dónde sale esta tipología de la 'Palabra'?]

La palabra de vida y su compromiso en la común-unificación y re-educación humana o de la sociedad mecano materialista, será la herramienta eje, el faro que guiará e iluminará el re-encuentro consigo mismo y con la otredad.

La palabra (más allá del idioma) tiene vida, tiene poder, posee comunicación profunda y se constituye en "camino de corazón", tiene su tiempo y su duración en las diferentes culturas que nos configuran como nativo-mestizos en la Colombia multiétnica y multi-conflictiva.

La palabra, en sus diferentes connotaciones será el alimento para la re-humanización nuestra y la re-indianización de nuestros hermanos ancestrales. Como alimento integrado posee las siguientes características:

La palabra como ley de origen, es la que está en nuestro pensamiento, nutre los sentidos, se constituye en el instinto, en el inconsciente colectivo, en la pulsión de vida y muerte.

La palabra como ley de amor, unifica nuestro cuerpo de creencias, facilita las alianzas tribales y societarias, genera confianza y transparencia discursiva, enlaza sentimientos y emociones; desde lo afectivo, permite la enseñanza mutua e innovadora, genera relacionamiento co-creativo en la diferencia, permite disoñar o soñar juntos y crea la conciencia, como rectora y arrojadora de luz y sabiduría divina a nuestras diferentes dimensiones humanas.

La palabra como ley del mundo, es la causa-efecto de la multiculturalidad, del complejo proceso del aprendizaje significativo 
y constructivo, de la asimilación conceptual y virtual de la realidad concreta. Su praxis es el reconocimiento. La palabra, en su trialéctico poder de ser instinto, reconocimiento $y$ conciencia, simboliza el "bastón para no caer"; bien utilizada, nos conducirá al despertar de la conciencia ontocósmica, cambiando nuestra posición frente a la madre tierra (La Pacha mama), la naturaleza y las relaciones con los humanos y demás seres terrestres.

Nuestra comunidad educativa, utilizará y se servirá de la palabra como herramienta comunicativa interna y externa y la hará ser más poderosa como estrategia integradora de la multidiversidad etnocultural que nos constituye. Será una nueva ética (noética) o energía conciencia para urdir una sana tejedura en nuestros cuerpos humanos (energías naturalespueblos); espiritual (retorno a la naturaleza, a las entidades y energías que nos alimenta, a la voluntad divina) y Mental (re-educación humana, correctas relaciones, derechos $\mathrm{y}$ deberes humanos).

La condición actual de nuestro planeta es el resultado del mecanismo de retroalimentación; si queremos ver cambios en nuestro mundo, debemos convertir esos cambios en nuestras vidas cotidianas. Debemos y estamos obligados conscientemente a vivir al máximo las oportunidades de cada día, ser capaces de percibir la belleza y misterios que despliega cada día y asumirlo como un desafío por venir, constituirnos en un fractal de la nueva sociedad y de la nueva conciencia, celebrando el aroma del triunfo individual y colectivo y de la renovación perceptual inexorable de re-significar el mundo.

Nuestra comunidad educativa está soportada en un triángulo de energías correlativas, voluntad: conciencia; amor: sabiduría divina; inteligencia: activa luz creadora y magnética y eso nos potesta como la punta de lanza de la ciencia y su misterio para apropiarnos de la mecánica cuántica, de la teoría de las supercuerdas, del hiperespacio, del orden implicado, de la holografía, de la teoría general de sistemas, la teoría del caos, del campo unificado, de la antimateria, de los atractores, la cualidad fractal, los campos morfogenéticos, la teoría gaia, la cibernética, los sistemas complejos, la medicina bio-energética, la psicología transpersonal y cooperar en la transformación material, mental y espiritual del ser y de la comunidad.

Nuestro aporte, en la actual coyuntura sociohistórica post-conflicto colombiana, ha sido la de abordar nuestras comunidades indígenas próximas (Tierradentro, Coyaima, Natagaima, Ataco) y hacer tejedura convivencial de nuestros estudiantes con los colectivos Páez y Pijao y aceptarlos e incorporarlos en su diferencia e identidad en nuestra bitácora de itinerantes viajeros planetarios.

Somos conscientes y consecuentes con la máxima sabia de que todos somos maestros y nuestra guía es interior, donde la palabra es nuestro ser. De ahí que nuestra tarea, al ser multidimensional, exige un compromiso declarativo, a través de nuestra palabra en los siguientes frentes:

- Implementación Individual - Personal: Integración y cambio en el tratamiento con la familia, hijos, pareja, hermanos, padres, compañeros. Autoobservación, autodisciplina, auto aceptación.

- Terrenal: Continuar con todos los trabajos e iniciativas de restauración, implementación de alternativas, transformación social, organizacional y concientización de las comunidades, reconocimiento mutuo inter redes, local y planetario.

- Mental-Cerebral: Armar el rompecabezas mente-cuerpo-espíritu, en una imagen integradora delos tiemposy evolución dela tierra, anclarnos en una nueva conciencia que rompa el modelo modernista alienante e insensible (con una nueva concepción como la trasmodernidad), disuelva las fronteras limitantes y separatistas de todo tipo (implementando la translocalidad) y soñando en colectivo nuevas formas de comunicación y creación edificante(disoñación).

[Para que esto no se interprete como filosofía barata o peor, un sinsentido, es preciso, como lo ha hecho Morin, proponer actividades puntuales dentro de los programas curriculares 
de las asignaturas (cuando se trata de la Escuela) o dentro de contextos como los diálogos para la conciliación, manifestaciones e incluso eventos que convocan a la gente.]

Para llevar a cabo esta tarea, requerimos en nuestra comunicación profunda, convertir la palabra en el aire de la vida de la tradición oral (oralitura [Hay que legitimar el término, citar sus fuentes, su pertinencia. Recuerden el 'sentipensante' , el 'hombre hicotea' de Fals Borda]), incorporar la esencia de los idiomas aborígenes, donde la palabra rezada es corazón palpitante, bálsamo curativo, ritual de la palabra para matar el frío que anida en nuestro corazón.

La palabra hablada, es un espiralado oral para ritual izar la comunicación y re-direccionar nuestro pensamiento; la palabra cantada, será la palabra obra y co-creación musical y poética con la otredad; la palabra siseada, despertará una atención extrema; la palabra decisoria será para los momentos definitivos y definitorios; la palabra narrativa, para hablar de historia, de mitos, vivencias y leyendas; la palabra Lúdrica, como oración colectiva, como control comunitario, a través del baile, del goce olásmico, del dar gracias; la palabra inútil, reconociéndola como la especular, que desarrolla disquisiciones teóricas o una sapiencia que no tiene aplicación práctica; la palabra desviada, como la que no corresponde al tema que se está tratando; la palabra de la calle, como metáfora que alude al chisme, al rumor o la calumnia; y la palabra vacua, o vacía que no dice nada.
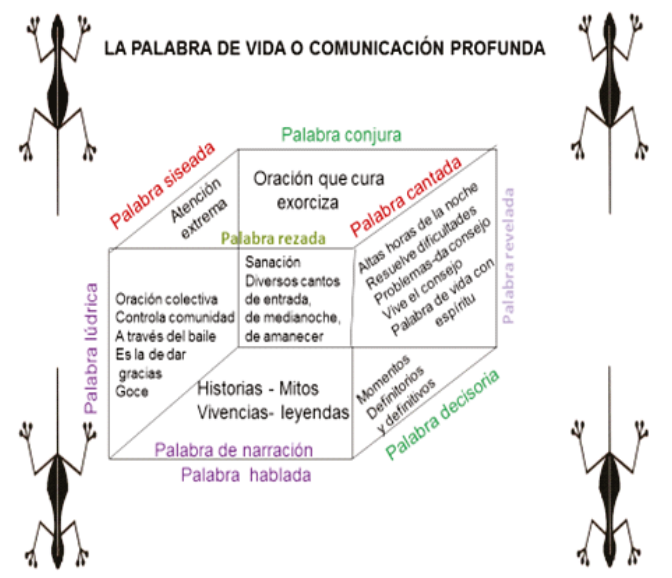

[¿Cuál es la fuente de los diagramas? ¿Cuál es su pertinencia para la propuesta?]

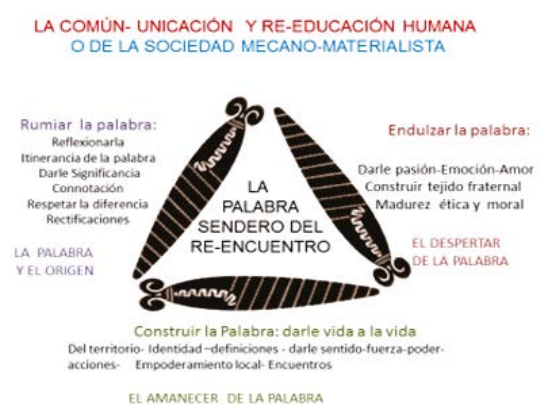

LA PALABRA DE VIDAO COMUNICACIÓN PROFUNDA: "EL CAMINO DE CORAZÓN"

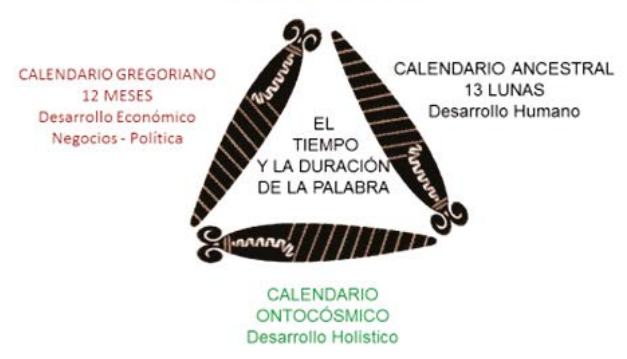

ALIMENTOS PARA LA RE-HUMANIZACIÓN

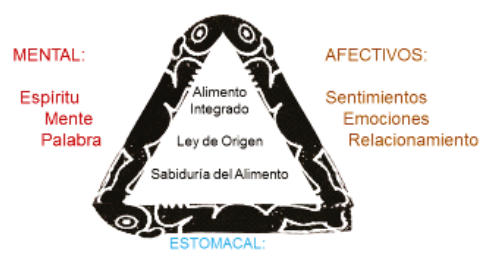

Palabraltinerante: alimento intercultural $\longrightarrow$ ingestión creciente y sabia. Si cuidas tu palabra ella te culdard.
Ley de Origen: Io que esta en el pensamiento
Vuelo del collibri Despertarla Globalización del Re-encuentro: porqué; para qué; en dónde..

ESTRATEGIAS DE INTEGRACION COMUNICATIVA INTERNA Y EXTERNA DE NUESTRA COMUNIDAD EDUCATIVA

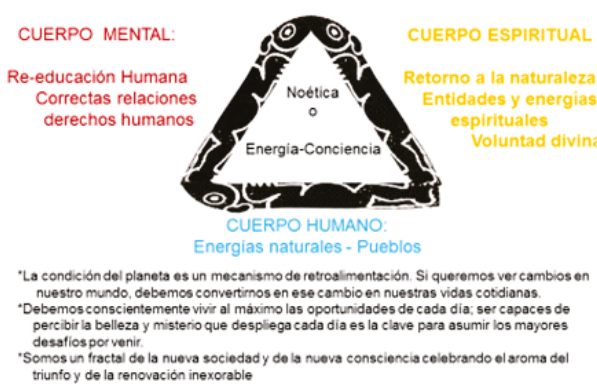


ESTRATEGIAS DE INTEGRACIÓN COMUNICATIVA INTERNA Y EXTERNA DE NUESTRA COMUNIDAD EDUCATIVA

INTELIGENCIA

Activa o luz creadora Magnetismo

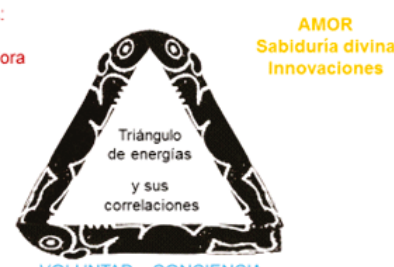

Somos la punta de lanza de la ciencia y su misterio: la mecanica cuantica, la teoria de las supercuerdas, el hiperespacio, el orden implicado, la hol cogrenta, la teoria general de sistemas. Ia teoria del caos, del campo unificado. de la antimateria, de los atractores, la cualidad fractal, los energebtca, la Psicologiatranspersonal.

EL DESPERTAR DE LA CONCIENCIA ONTOCÓSMICA "LA PALABRA SIMBOLIZA EL BASTOON PARA NO CAER"

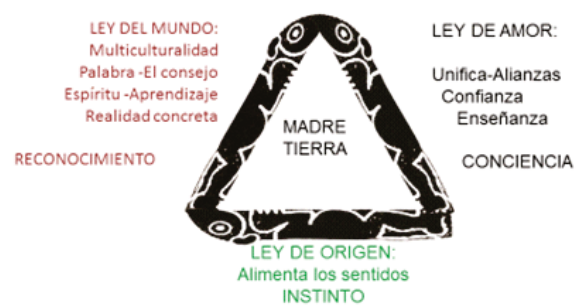

LAS TRES HERRAMIENTAS DE LA RENOVACIÓN HUMANA "LA MULTIDIMENSIONALIDAD"

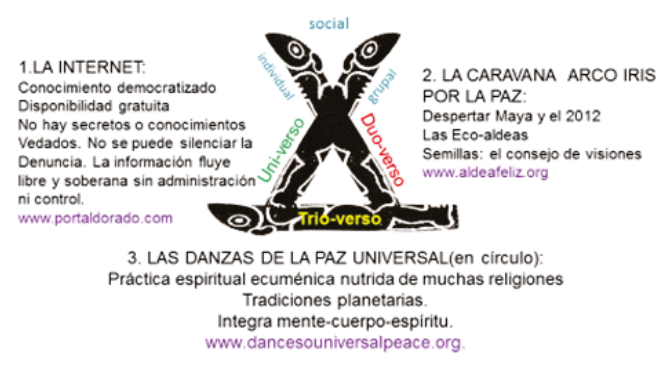

EL MAESTRO SOMOS TODOS Y LA GUIA ES INTERIOR "EL SER ES SU PALABRA"

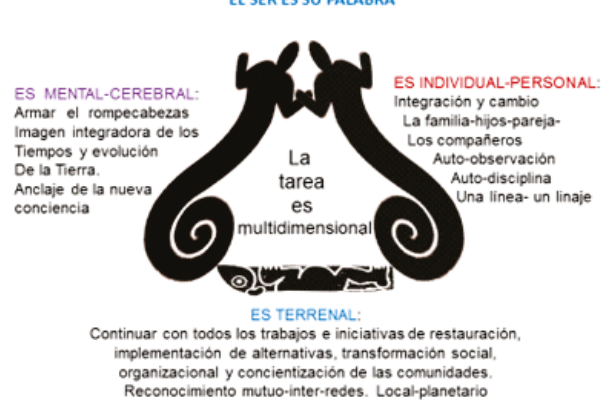

PALABRADE VIDA O COMUNICACIÓN PROFUNDA "EL AIRE DE VIDA DE LA TRADICIÓN ORAL"

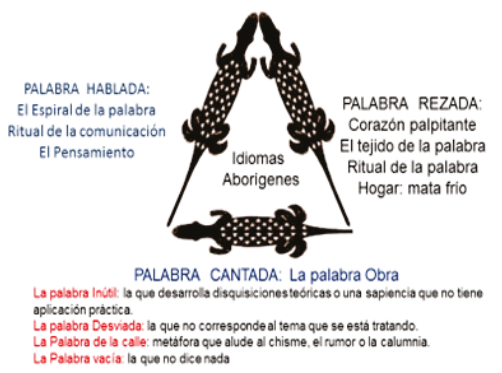

[Se debe hacer una síntesis de lo planteado y formular posibles proyecciones. Hay que enriquecer las referencias bibliográficas]

\section{Referencias bibliográficas}

Duque Gómez, L. y otro. (1979). Arqueología de San Agustín, Alto de los Ídolos, montículos y tumbas. Bogotá: Lit. Arco.

Fals Borda, O. (1980). La ciencia y el pueblo: nuevas reflexiones sobre la investigación-acción, en Asociación Colombiana de Sociología, La sociología en Colombia: balance y perspectivas, Memoria del Tercer Congreso Nacional de Sociología, Bogotá, 20-22 de agosto de 1980, pp. 149-174

Leal, J. U. (2007). Mestizajear pedagógico nómada de re-humanización de la Coyaima indígena y su metodología del colibrí.

Leal, J. U. (2008). Caminando la palabra en la tradición oral de la Coyaima indígena mediante la pedagogía nómada del colibrí,

Leal, J. U. (2009). De los utópicos ancestrales litolenguajeros a los disutópicos co-creadores colombianos siglo XXI.

Leal, J. U. (2010). Ataco: Una tejedura pedagógica de re-humanización de la comunidad indígena ICO del valle de Anapé-Tolima

Leal. Z. José Uriel. Una percepción del mundo Mito poético y pensamiento cosmogónico de los ancestrales litolenguajeros del Huila. Octubre de 2016. Biblioteca U.de.C. Girardot;

Zabala. G. E. (2009). La ensoñación de los saberes: nomadología del pedagogiar; introducción al cerebro social. Cali: Universidad Libre. 